\title{
Treating Site
}

National Cancer Institute

\section{Source}

National Cancer Institute. Treating Site. NCI Thesaurus. Code C93477.

Any healthcare facility where care is provided as part of a cooperative group. 